\title{
An investigation of auditory contagious yawning
}

\author{
STEPHEN R. ARnotT \\ Rotman Research Institute, Toronto, Ontario, Canada \\ and University of Western Ontario, London, Ontario, Canada \\ ANTHONy SinghaL \\ University of Alberta, Edmonton, Alberta, Canada \\ AND \\ Melvyn A. Goodale \\ University of Western Ontario, London, Ontario, Canada
}

\begin{abstract}
Despite a widespread familiarity with the often compelling urge to yawn after perceiving someone else yawn, an understanding of the neural mechanism underlying contagious yawning remains incomplete. In the present auditory fMRI study, listeners used a 4-point scale to indicate how much they felt like yawning following the presentation of a yawn, breath, or scrambled yawn sound. Not only were yawn sounds given significantly higher ratings, a trait positively correlated with each individual's empathy measure, but relative to control stimuli, random effects analyses revealed enhanced hemodynamic activity in the right posterior inferior frontal gyrus (pIFG) in response to hearing yawns. Moreover, pIFG activity was greatest for yawn stimuli associated with high as opposed to low yawn ratings and for control sounds associated with equally high yawn ratings. These results support a relationship between contagious yawning and empathy and provide evidence for pIFG involvement in contagious yawning. A supplemental figure for this study may be downloaded from http://cabn.psychonomic-journals .org/content/supplemental.
\end{abstract}

One of the more curious aspects observed in human behavior is the tendency to adopt the gestures and postures of others (e.g., the chameleon effect; Chartrand \& Bargh, 1999). Perhaps the most well-known example of this is contagious yawning (i.e., the act of yawning or the urge to yawn in the presence of another person yawning; Provine, 1986). The widespread familiarity of contagious yawning is due in part to the fact that almost everyone has experienced the phenomenon and that it occurs seemingly without volition. Indeed, even the mere thought of yawning (e.g., reading about it) can be enough to incite contagious yawning (Provine, 1986). Despite the near universality of this phenomenon, however, research investigating the cortical mechanisms underlying contagious yawning, although providing many advances, has yet to fully explain its neural basis (Provine, 2005). A thorough understanding of the neural underpinnings of contagious yawning is important for an understanding of the behavioral and perhaps the communication systems of human and nonhuman species, and it may be particularly relevant to revealing why certain human populations demonstrate absent or aberrant forms of mimicry (e.g., autism; see Rogers, Hepburn, Stackhouse, \& Wehner, 2003).

Recently, a potential advance in the understanding of contagious yawning has arisen with the discovery of mir- ror neurons (MNs). These cells, located in the posterior inferior frontal gyrus (pIFG) of monkeys and assumedly humans (Fadiga, Fogassi, Pavesi, \& Rizzolatti, 1995; Rizzolatti \& Craighero, 2004), become active when an animal performs a particular action as well as when it perceives another perform that same action (di Pellegrino, Fadiga, Fogassi, Gallese, \& Rizzolatti, 1992; Gallese, Fadiga, Fogassi, \& Rizzolatti, 1996; Rizzolatti \& Craighero, 2004; Rizzolatti, Fadiga, Gallese, \& Fogassi, 1996). Accordingly, MNs provide a basis for action understanding (Rizzolatti \& Craighero, 2004) and may form part of the neural substrate underlying imitative actions (Jeannerod, 1994; but see Makuuchi, 2005) — capacities both relevant to the phenomenon of contagious yawning. There is also speculation that the MN system extends into visceromotor brain centers, thereby enabling the experiential understanding of others' emotional states (Gallese, Keysers, \& Rizzolatti, 2004; Keysers \& Gazzola, 2006; Wicker et al., 2003). Here too, a putative link with contagious yawning exists, because contagious yawning appears to be part of the neural network involved in empathy (Platek, Critton, Myers, \& Gallup, 2003; Platek, Mohamed, \& Gallup, 2005). Accordingly, there is reason to speculate that IFG cells may contribute to the phenomenon of contagious yawning (Provine, 2005). That said, null findings from two fMRI investigations of 
contagious yawning (Platek et al., 2005; Schürmann et al., 2005) have called this hypothesis into question, leading to speculation that cells in the pIFG seem to be circumvented when a yawn is observed. It is possible, however, that contagious yawn-related hemodynamic activity in those studies was obscured by issues of experimental design (e.g., block designs and task requirements) that rendered it impossible to selectively average only those yawn stimuli that actually elicited an urge to yawn in each participant. In addition, it is arguable that some of the control stimuli used in those experiments were also $\mathrm{MN}$ stimulating, further reducing the likelihood of observing pIFG activity in response to observing yawns.

In the present auditory fMRI study, we reexamined the neural underpinnings of contagious yawning, this time using an event-related experimental design in which participants rated how much each stimulus made them feel like yawning. In this way, it was possible to isolate hemodynamic activity associated with those yawn stimuli that elicited strong urges to yawn (i.e., contagious yawning) within each participant. An auditory approach was adopted primarily because a formal investigation was needed to support the widely held, although largely anecdotal (Moore, 1942), notion that the sound of a yawn elicits contagious yawning. Like visual images, sounds are also effective MN stimulators (Gazzola, Aziz-Zadeh, \& Keysers, 2006; Keysers et al., 2003; Kohler et al., 2002; Pazzaglia, Pizzamiglio, Pes, \& Aglioti, 2008; Rizzolatti \& Craighero, 2004), and so an auditory paradigm was considered to be a valid test of the MN hypothesis.

\section{METHOD}

\section{Participants}

Ten experimentally naive, right-handed persons (mean age $=$ 27.7 years, $\pm 4.2 S D$, normal hearing, 4 males) with prior fMRI experience were recruited and remunerated. All provided written and informed consent according to the Review Board for Health Sciences Research Involving Human Participants for the University of Western Ontario and the Robarts Research Institute (London, Ontario, Canada).

\section{Acoustic Stimuli}

In a soundproof chamber, 13 volunteers emitted eight or more natural yawns (Y) - an audio loop of prerecorded yawn stimuli was made available over headphones to help induce yawning - and breaths (B) into an omnidirectional microphone (Sony ECM-T115) located $40 \mathrm{~cm}$ from the mouth. Eight listeners rated each of the 155 Y recordings on a 3-point scale, where $1=$ artificial sounding, $2=$ realistic, $3=$ very realistic. The four highest-rated yawns from the 10 most highly rated yawners (5 males) were selected, creating 40 experimental Y stimuli. Selected Ys received an overall mean rating of $2.56( \pm 0.27 S D)$. The $40 \mathrm{~B}$ sounds were selected and trimmed to match the duration $( \pm 0.1 \mathrm{sec})$ and source (i.e., the person who produced it) of each yawn clip. All sounds were recorded at $48 \mathrm{kHz}$ (16 bit, mono), had a mean duration of $6.0 \mathrm{sec}( \pm 1.16 \mathrm{SD})$, and were amplitude normalized (Adobe Audition software, V1.0).

Forty scrambled yawns $(\mathrm{X})$ were also created from each Y stimulus by temporally reversing each $300-\mathrm{msec}$ segment in each waveform (typically 20 reversals per waveform). Thus, for any given Y stimulus, there existed a corresponding X stimulus that had virtually the same amplitude, overall temporal envelope information, and frequency content (with the exception of a small amount of transi- tion energy created at each reversal point). X stimuli were described as "choppy," "unnatural," and "not contagious."

\section{Design and Procedure}

Following experimental instructions, participants lay in the MRI machine with surgical tape affixed across their forehead to reduce head motion. Each finger of their right hand was placed on a separate button of a four-button response pad. Digitized sounds were converted to an air signal (pneumatic, nonmagnetic transducer) and sent through two channels to acoustically padded (30-dB attenuation) circumaural, fMRI-compatible headphones (Resonance Technology, Northridge, CA) at an intensity that each participant judged to be comfortably audible over the background scanner noise.

The fMRI experiment contained 120 (40 each of Y, B, and X) unique sounds, randomized over eight blocks (i.e., 15 trials per block). Each $20-\mathrm{sec}$ trial began with a $100-\mathrm{msec}, 1000-\mathrm{Hz}$ alerting tone followed $900 \mathrm{msec}$ later by the auditory stimulus. Participants were asked to lie still in the MRI machine and indicate how strongly they felt an urge to yawn by using a 4-point scale ( 1 = in no way felt like yawning, 2 = felt like yawning a little, $3=$ strongly felt like yawning, 4 = actual/stifled yawn). Approximately $13 \mathrm{sec}$ of silence (baseline hemodynamic activity) followed sound offset. Total duration of the functional experiment was approximately $45 \mathrm{~min}$.

\section{Data Acquisition}

Scans were conducted with a 4-T Siemens Varian whole-body MR scanner (Siemens, Erlangen, Germany; Varian, Palo Alto, CA) with a standard cylindrical quadrature head coil. Functional imaging was performed to measure the BOLD effect with optimal signal contrast. For functional scanning, 17 contiguous axial slices were acquired (navigator echo-corrected, slice-interleaved two-shot, T2*weighted, echo-planar imaging pulse sequence: volume acquisition time $=2,000 \mathrm{msec}$, repetition time $[\mathrm{TR}]=1,000 \mathrm{msec}$, echo time $[\mathrm{TE}]=15.0 \mathrm{msec}$, flip angle $=45^{\circ} ; 22.0-\mathrm{cm}$ field of view [FOV], $3.4 \times 3.4 \times 6.0 \mathrm{~mm}$ voxel size, $64 \times 64$ effective acquisition matrix). Functional scans were aligned to a high-resolution volumetric anatomical MRI (obtained after the functional runs) consisting of single-shot, inversion time (T1) weighted images collected with the same slice orientation (3-D magnetization-prepared turbo FLASH acquisition with $\mathrm{T} 1=750 \mathrm{msec}, \mathrm{TR}=45 \mathrm{msec}, \mathrm{TE}=3.0 \mathrm{msec}$, $22.0 \times 22.0 \mathrm{~cm}$ FOV, $256 \times 256$ acquisition matrix, 128 axial slices, $0.9 \times 0.9 \times 1.5 \mathrm{~mm}$ voxel size).

\section{Data Analysis}

Brain Voyager (BV) QX software (V1.7, Brain Innovation, Maastricht, The Netherlands) was used for fMRI analyses. Functional data underwent linear trend removal, high-pass filtering ( 3 cycles), and serial correlation correction (a BV script that adjusts the standard error of the beta weights in order to avoid the problem of inflated $t$ values associated with the autocorrelation of neighboring measurement time points). Functional scans were coregistered and transformed into Talairach space (Talairach \& Tournoux, 1988). Functional data were neither slice scan-time corrected (because of the multishot acquisition technique) nor spatially smoothed.

Prior to any preprocessing, time-course movies of the individual runs for each participant were examined and quantitatively evaluated using the BV 3-D motion correction algorithm, ensuring head motion $<1 \mathrm{~mm}$ in translation and/or $1^{\circ}$ in rotation. Moreover, functional activity most likely contaminated by motion artifacts (i.e., activity associated with stimuli rated as 4 [actual/stifled yawn]) was omitted from the analyses. Such precautions eliminated the need to apply motion correction algorithms to the data.

The reference hemodynamic-related function was defined by BV's two-gamma hemodynamic response function (onset of curve = $0 \mathrm{msec}$, time-to-response peak $=5 \mathrm{sec}$, response dispersion $=1$, undershoot ratio $=6$, time-to-undershoot peak $=15 \mathrm{sec}$, undershoot dispersion $=1$ ). Separate predictors were created for the alerting tone, each sound type, and each participant. 
To ensure that the results could be generalized to the population level, a random-effects, two-way conjunction analysis was carried out with the aim of revealing brain regions activated by yawn sounds (i.e., $\mathrm{Y}>\mathrm{B} \cap \mathrm{Y}>\mathrm{X}$ ). Under random-effects analyses, each participant is treated as a random sample from the population of all people, with 10 being the minimum number of participants recommended by Brain Voyager (see www.brainvoyager.de/BV2000OnlineHelp/ BrainVoyagerWebHelp/Random_effects_analysis.htm). To control multiple comparisons, we used a cluster size-thresholding procedure (Cox, 1996) employing a whole-brain correction criterion based on 1,000 Monte Carlo simulations. This procedure determined that, at an uncorrected voxel-level $p$ value of .01 , at least 135 voxels were required to attain a false-positive rate of $5 \%$.

A subsequent contagious yawn contrast $(\mathrm{Y} 3>\mathrm{Y} 1 \cap \mathrm{Y} 3>\mathrm{B} 3 \cap$ $\mathrm{Y} 3>\mathrm{X} 3$ ) further subdivided sound type predictors according to urge-to-yawn ratings $(1,2,3$, or 4$)$. Although data from all 10 participants were used, the analysis was necessarily a fixed-effects one, because not all participants generated enough responses to form reliable predictors for all sound types (for example, 1 participant produced only one $\mathrm{Y} 1$ and two $\mathrm{X} 3$ responses throughout the experimental session). Nevertheless, the three-way conjunction contrast ensured that this analysis remained a relatively conservative one. We created event-related hemodynamic response plots by extracting percent signal change values (BV file-based procedure; baseline = 2 TRs prior to onset) from activation clusters.

Finally, given reports of links between empathy and contagious yawning (Platek et al., 2003; Platek et al., 2005), as well as more empathic individuals showing greater hemodynamic activity in putative MN areas (Gazzola et al., 2006; Kaplan \& Iacoboni, 2006; Pfeifer, Iacoboni, Mazziotta, \& Dapretto, 2008), one-tailed Pearson correlation analyses were carried out. Correlations between empathy level and susceptibility to contagious yawning were conducted by using each participant's empathy level (determined by using the Empathy Quotient scale; Baron-Cohen \& Wheelwright, 2004) and yawn susceptibility (determined by calculating, for each participant, the difference between their mean urge-to-yawn rating of all yawn sounds and their mean urge-to-yawn rating of all control sounds). Correlations between empathy level and hemodynamic activity in brain regions activated during the perception of contagious yawns were conducted by correlating Empathy Quotient scale measures with the hemodynamic activity extracted from the brain regions. Such regional activity was defined as the percent BOLD signal value at the peak of the hemodynamic signal change (see the Results section). For each participant, a baseline measure of task-related activity (i.e., the average BOLD signal response across Y1-, B1-, and X1-rated stimuli) was subtracted from the BOLD signal associated with each high-rated urge-to-yawn stimulus (i.e., Y3, B3, and X3). These three values were then correlated with Empathy Quotient scale values.

\section{RESULTS}

We confirmed the popular belief that the sound of a yawn, like the sight of someone yawning, is effective at eliciting an urge to yawn. Yawn sounds received significantly higher urge-to-yawn ratings (mean rating $=2.2$, \pm 0.1 standard error $[S E M]$ ) than did either the scrambled yawns [1.6, $\pm 0.2 S E M ; t(9)=4.20, p=.002]$ or breaths $[1.5, \pm 0.1$ SEM; $t(9)=3.69, p=.005]$. These overall rating patterns are in agreement with those obtained from postexperimental self-report data describing the level of yawn urges in response to visual stimuli (Schürmann et al., 2005). In that fMRI study, postexperimental tendency-toyawn ratings for yawn and non-yawn videos were found to be $2.8( \pm 0.2 S E M)$ and $1.4( \pm 0.1 S E M)$, respectively, using a 5-point scale. In the present study, very few overt yawns were actually produced in the magnet, also con- sistent with that reported in the previous fMRI study (Schürmann et al., 2005). Although that study discouraged yawning behavior through the use of neck braces, participants in the present study were also discouraged through experimental requests to not induce any head/ body motion. Note too that the inhibition of yawning is thought to be under quasi-voluntary control (Baenninger \& Greco, 1991) and that overt yawning is often reduced in experimental circumstances in which participants feel that they are being observed/evaluated (Baenninger \& Greco, 1991).

The most interesting finding of the present study, however, was the observation of a systematic relationship between hemodynamic brain activity and yawn sound presentation. Compared with breathing sounds (also easily recognizable, natural, nameable, nonverbal human vocalizations produced by inhalation and exhalation) as well as the scrambled versions of the yawn sounds (which, apart from the temporal reversals, contained virtually the same acoustic properties and overall temporal envelope as the yawns), a general linear model conjunction analysis showed that yawn sounds were associated with significantly greater BOLD activity in frontal areas (see Figure 1). At $p=.01$, these included the left insula (739 voxels), left caudate head (371 voxels), right ventrolateral (301 voxels) and dorsolateral (248 voxels) prefrontal cortexes, and right Brodmann's area 44 (pIFG; 136 voxels). Despite a trend, left Brodmann's area 44 (pIFG; 115 voxels) did not meet the minimum cluster size (135 voxels) for statistical significance.

Of course, just because yawn stimuli received greater average yawn-likelihood ratings does not mean that the observed brain activations necessarily reflect contagious yawning. One possible counterargument is that, in our study, motor imagery was invoked that was related to the customary habit of covering one's mouth when yawning. However, this is unlikely because we did not observe parietal activation (Szameitat, Shen, \& Sterr, 2007) or handarea activation in primary motor cortex (Gazzola et al., 2006). Thus, it is more likely that our findings reflect the fact that listeners were identifying those stimuli as yawn sounds. To more closely examine this possibility, a second conjunction contrast was carried out identifying brain regions specifically activated by contagious yawn sounds. Here, BOLD activity in response to yawn sounds eliciting a strong urge to yawn (i.e., a rating of 3 ) was contrasted with (1) activity evoked by yawns eliciting very low urge-to-yawn ratings (i.e., a rating of 1), as well as with (2) activity associated with high urge-to-yawn breath and scrambled yawn sounds (i.e., a rating of 3 ). This analysis should have revealed areas of the brain that respond to yawn sounds but only when those sounds induce the urge to yawn (i.e., contagious yawns). Strikingly, the only cortical areas significantly activated under this conservative three-way contrast were the right pIFG (139 voxels) and the posterior superior temporal gyrus (pSTG; 220 voxels; see Figure 2 and Supplementary Figure 1). Activations that failed to meet the statistical threshold were located in the right insula $(39,2,10)$, posterior midbrain $(3,-34,-2)$, and medial frontal pole $(3,59,-3)$. 


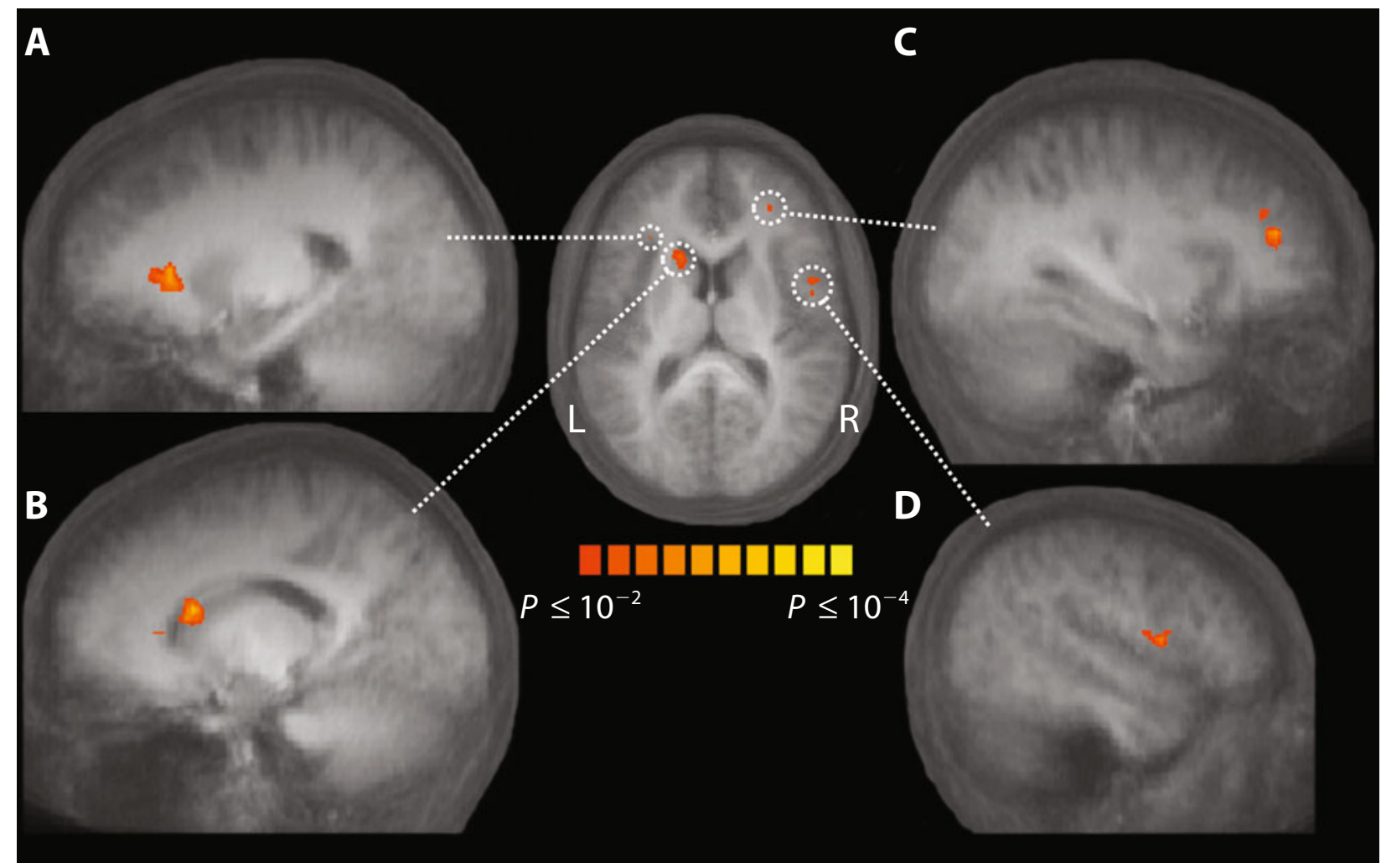

Figure 1. Cortical activation associated with yawn sounds. Conjunction contrast of yawns $>$ scrambled yawns $\cap$ yawns $>$ breaths. Cluster size $\geq 135$ voxels. Brain region and peak voxel Talairach coordinates $(X \mathrm{~mm}, Y \mathrm{~mm}, Z \mathrm{~mm})$ for each activation cluster: (A) left insula $(-21,23,7),(B)$ left caudate head $(-15,14,17),(C)$ right dorsolateral prefrontal cortex $(36,29,25)$ and right ventrolateral prefrontal cortex $(30,41,19)$, and $(D)$ right posterior inferior frontal gyrus $(48,5,10)$. Activation clusters are plotted on the "averaged" Talairach brain of all 10 participants.

Finally, the relationship between empathy scores and yawn measures was investigated. Previous studies have indicated a positive relationship between empathy levels and a person's susceptibility to contagious yawning (Platek et al., 2003; Platek et al., 2005). Indeed, a Pearson correlation analysis of each participants' yawn susceptibility measure (see the Method section) and empathy measure (i.e., their score on the Empathy Quotient scale) confirmed this hypothesis, revealing a modest, but significant, positive correlation (Pearson correlation, $r=.57$; $p<.05$, one-tailed; $n=10$ ). Similar findings have been reported with respect to more empathic people producing greater activation in putative MN areas (Gazzola et al., 2006; Kaplan \& Iacoboni, 2006; Pfeifer et al., 2008). Accordingly, we also carried out correlation analyses between empathy scores and the peak activity in the right pIFG (i.e., $10 \mathrm{sec}$ after sound onset; see Figure 2) as it pertained to Y3, B3, and X3. Here too, significant correlations were found between empathy measures and pIFG hemodynamic activity. Specifically, the amount of hemodynamic activity associated with highly rated yawn and breath stimuli, but not scrambled yawns, were found to be positively correlated with Empathy Quotient scores (Pearson correlation values of .57 and .66 , respectively; $p=.05$ and .04 , respectively, one-tailed; $n=9$ owing to the fact that 1 participant did not produce enough $\mathrm{Y} 3, \mathrm{~B} 3$, or $\mathrm{X} 3$ responses to form a reliable BOLD signal measures). No such correlations were found in the right pSTS (posterior superior temporal sulcus) at $8 \mathrm{sec}$ postonset (i.e., the peak of the response) nor at the time points before or after that peak (i.e., 6 or $10 \mathrm{sec}$ postonset; all $p \mathrm{~s}>.2$ ).

\section{DISCUSSION}

Our results clearly show that hearing someone yawn not only increases a person's urge to yawn, but that it activates brain areas that (1) have been shown to be involved in hearing and executing mouth actions (Gazzola et al., 2006), and (2) are necessary for recognizing the actions of others (Pazzaglia et al., 2008). Accordingly, our findings link contagious yawning to the human MN network (Rizzolatti \& Craighero, 2004). In fact, the more contagious the yawn stimulus was, the more these regions (i.e., pIFG and pSTG) were activated. Such activity cannot easily be explained by appealing to notions of yawn suppression (e.g., the activation was the result of participants inhibiting the urge to yawn while undergoing a movement-sensitive fMRI scanning procedure), because the yawn stimuli associated with high urge-to-yawn ratings still generated more BOLD activity in these regions than did the control stimuli associated with equivalently high urge-to-yawn ratings (compare Y3, B3, and X3 responses in Figure 2). 


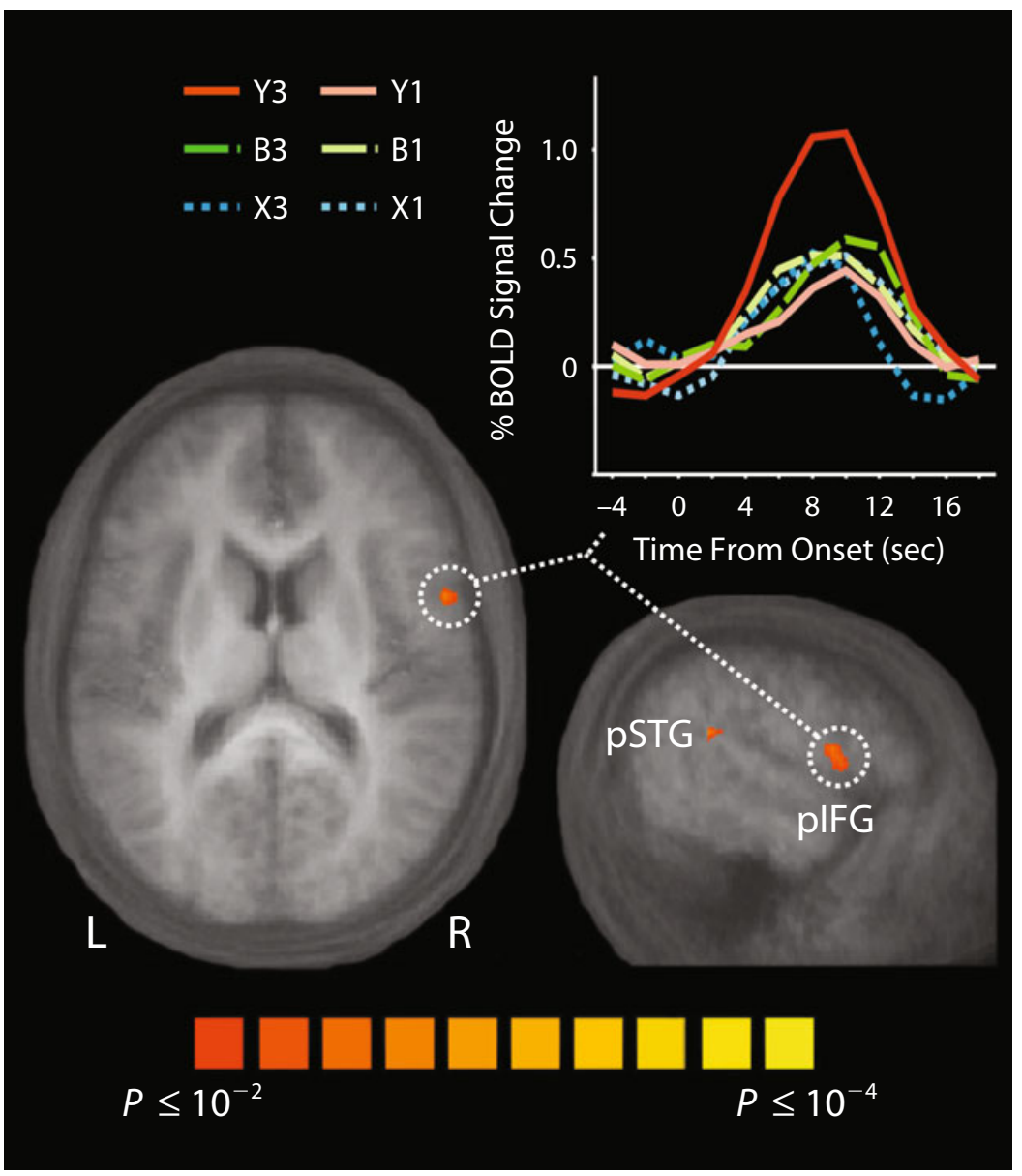

Figure 2. Cortical activation associated with contagious yawn sounds. Conjunction contrast of 3-rated yawns (Y3) $>1$-rated yawns $(\mathrm{Y} 1) \cap \mathrm{Y} 3>3$-rated scrambled yawns (X3) $\cap$ Y3 $>3$-rated breaths (B3). Cluster size $\geq 135$ voxels. Brain region and peak Talairach coordinates $(X \mathrm{~mm}, Y \mathrm{~mm}, Z \mathrm{~mm})$ for each activation cluster: right posterior superior temporal gyrus (pSTG; $57,-37,19)$ and right posterior inferior frontal gyrus (pIFG; 54, 5, 11). Graph plots event-related BOLD responses in the right PIFG for the above conditions, and 1-rated scrambled yawns (X1) and breaths (B1). See also Supplementary Figure 1 (online).

These findings are all the more significant given that prior fMRI studies argued against pIFG involvement in contagious yawning (Platek et al., 2005; Schürmann et al., 2005). As in our study, yawn-specific activation had been observed in the right posterior superior temporal lobe, perhaps related to the processing of socially relevant biological motion and its imitation (Iacoboni, 2005; Schürmann et al., 2005 ) or to the fact that the stimulus was a mouth action sound (Gazzola et al., 2006). But neither of the previous contagious yawning studies found that watching people yawn resulted in differential pIFG activation when compared with watching people laugh (Platek et al., 2005) or move their tongue in their cheek (Schürmann et al., 2005). This has prompted speculation that contagious yawning is an automatically released behavior that circumvents the essential parts of the MN system (Schürmann et al., 2005).

On reflection, however, it seems possible that yawnrelated pIFG activity in those studies could have been masked by activity elicited by the control conditions. Laugh- ing, for instance, is also a contagious behavior (Provine, 2005) that can invoke right pIFG activity during both its perception and expression (Meyer, Baumann, Wildgruber, \& Alter, 2007). Similarly, the tongue-in-cheek control condition used by Schürmann et al. (2005) may also have elicited an imitation neural response, given that human MNs are believed to respond even to movements that are not goal directed (Rizzolatti \& Craighero, 2004). Indeed, when the results from that study are reexamined, pIFG activation is noticeably present for both the yawn and tongue stimuli (Schürmann et al., 2005, Figure 2, p. 1262). Moreover, the activation appears to be stronger in the right IFG and also appears greatest for the yawn stimuli. In the present study, the control stimuli (i.e., the scrambled yawn sounds) may be considered more "action benign" in the sense that they were artificially created, physically impossible stimuli.

Second, it is very likely that the block design nature of the previous studies reduced the ability to isolate contagious yawn hemodynamic activity. Clearly, contagious 
yawning does not always occur every time a yawn stimulus has been perceived. Although some yawn stimuli are more effective than others, a stimulus that is effective for one person may not be so for another. Furthermore, there is most likely variation even within a given individual from one occasion to the next. Unlike the previous designs, the online rating technique of the present eventrelated experiment enabled us to identify and isolate brain responses to yawn sounds that were experienced as contagious compared with those that were not. That said, it is unclear to what extent the yawning judgments themselves (i.e., the urge-to-yawn ratings) affected the activity observed in response to contagious yawns. Although we do not deny that being cognizant of yawning may prime a person to be more susceptible to contagious yawning, this should not invalidate the present results. Indeed, people are known to be more susceptible to yawning under different circumstances (Provine \& Hamernik, 1986), and many would agree that there are occasions in which one is more susceptible to contagious yawning than others (e.g., in situations were attention is not strongly focused on a task at hand). This makes the point that, in some respects, contagious yawning may rely on some form of embodiment or mental reflection of the yawn that has been perceived, be it at its most basic, perhaps subconscious, level (see also Walusinski, 2006).

\section{Contagious Yawning and MNs}

Our finding of contagious yawn-related activity in what is thought to be the hub of the MN system (i.e., the pIFG; Rizzolatti \& Craighero, 2004) is not the only datum consistent with an $\mathrm{MN}$ hypothesis of contagious yawning. First, it has been argued that the human MN system is not functional at birth but develops some time after 6 months of age (Falck-Ytter, Gredebäck, \& von Hofsten, 2006). It is noteworthy that, as an antecedent to any MN-mediated behavior, human contagious yawning is reportedly not exhibited until some time after the second year of life (Anderson \& Meno, 2003; Piaget, 1951), despite the fact that spontaneous yawning is readily exhibited by infants, newborns, and even fetuses (Egerman \& Emerson, 1996; Sepulveda \& Mangiamarchi, 1995). This incidentally implicates a perceptual and/or cognitive component as being central to contagious yawning (Lehmann, 1979; Platek et al., 2005).

Also, children with autism, a disorder that may be related to MN-system abnormalities (Oberman \& Ramachandran, 2007), show a marked reduction in contagious yawning despite exhibiting "normal" spontaneous yawning behavior (Senju et al., 2007). Our findings show a positive correlation between a person's susceptibility to contagious yawning and how empathic they are. Furthermore, individuals who were more empathic showed greater right $\mathrm{pIFG}$ activations to contagious yawn sounds, consistent with the idea that the MN system is central to social cognition (Gazzola et al., 2006; Kaplan \& Iacoboni, 2006; Pfeifer et al., 2008). Lastly, akin to the fact that MNs are suspected only in certain populations (e.g., primates; Rizzolatti \& Craighero, 2004), it is interesting that contagious yawning has been documented in only humans, chimpanzees (Anderson, Myowa-Yamakoshi, \& Matsuzawa, 2004), and (questionably) macaques (Paukner \& Anderson, 2006), ${ }^{1}$ despite the fact that a vast array of vertebrate species are known to exhibit spontaneous yawning (Baenninger, 1987).

Given that classically defined MN-mediated behaviors are considered to be those that invoke mirror cell activity during the observation as well as the execution of the relevant behavior (Rizzolatti \& Craighero, 2004), one might expect the pIFG also to be active when a person yawns. However, because of the stereotypical head movements associated with the act of yawning (Deputte, 1994; Provine, 1986; Redican, 1975), this question is difficult to directly assess with functional neuroimaging. Nevertheless, there is good reason to believe that the PIFG may be associated with yawning. First, it has been reported that a patient with Foix-Chavany-Marie syndrome, a form of pseudobulbar palsy resulting from bilateral opercular lesions, was unable to yawn voluntarily (whether spared involuntary yawning was spontaneous and/or contagious is unclear; Laurent-Vannier, Fadda, Laigle, Dusser, \& Leroy-Malherbe, 1999). Second, and more convincingly, recent fMRI investigations of mouth movements have shown that very proximal, if not the same, regions of the pIFG in BA44 are activated when participants are asked to smile (Warren et al., 2006), imitate facial expressions (Lee, Josephs, Dolan, \& Critchley, 2006; van der Gaag, Minderaa, \& Keysers, 2007), manipulate small objects with their lips (Gazzola et al., 2006), listen to pure mouth sounds (e.g., crunching a piece of candy with the teeth, kissing, gurgling, crunching potato chips, finishing a can of soft drink with a straw; Gazzola et al., 2006), or listen to nonverbal human vocalizations (Warren et al., 2006).

Although what functional or evolutionary advantage that contagious yawning confers is unknown, one popular hypothesis is that it serves as some type of communicative gesture - that is, to synchronize moods in gregarious animals (Deputte, 1994), or to increase vigilance (Daquin, Micallef, \& Blin, 2001; Gallup \& Gallup, 2007). Certainly, the left pIFG is important for the production of verbal communication signals (Pazzaglia et al., 2008), and the homologous region in the right hemisphere appears to be important for nonverbal acoustic signals (Meyer \& Jäncke, 2006). In fact, both brain regions activated during the perception of contagious yawns in the present study (i.e., right pIFG and pSTG) are thought to be part of a gesture-recognition network (Villarreal et al., 2008). In this regard, the right pSTG activation that correlated with yawn contagiousness ratings could also be viewed as a node for abstract (i.e., nonlexical) language comprehension (Bookheimer, 2002; Gernsbacher \& Kaschak, 2003; Jung-Beeman, 2005).

\section{pIFG Neurons: Triggers for Contagious Behavior?}

Inferior prefrontal hemodynamic activity previously has been shown to increase with the amount of explicit imitation that a person exerts (e.g., using a facial imitation task; Lee et al., 2006), and more recently, this region has been shown to become active when unconscious word 
primes representing actions are presented to an observer (Galati et al., 2008). Furthermore, Warren et al. (2006) not only reported increased pIFG activity when people passively listened to nonverbal human vocalizations, they also found concurrent increases in the electromyographic activity of lower facial muscles, suggesting that orofacial gestural responses are engaged automatically when such stimuli are perceived. In this context, our novel finding of ventral prefrontal activity concurrently increasing with contagious impulses (i.e., the urge to carry out the behavior) leads to speculation that pIFG activation may play a role in eliciting the actual contagious event. Such conjecture will, of course, require further research.

Finally, as alluded to earlier, it is likely that attention also has a role in modulating contagious behaviors. For example, Lee et al. (2006) found that the inferior prefrontal activity associated with the imitation of facial expressions was essentially eliminated when participants were asked to perform a gender discrimination task on the same facial stimuli. This, combined with similar findings from other studies, prompted Lee et al. to speculate that the MN system may be attenuated when attention is focused on anything other than the posture or behavior to be imitated. Although this too will require further investigation, one can certainly imagine a need for such a mechanism. Indeed, without a way of modulating urges to imitate, goaldirected activities would be subject to constant disruption in environments ripe with social cues.

\section{AUTHOR NOTE}

This research was supported by grants from the Canadian Institutes of Health Research to S.R.A. and M.A.G. We thank Kathy Maxwell for preparing the stimuli and Christian Keysers and one anonymous reviewer for helpful comments on an earlier version of the manuscript. Address correspondence to S. R. Arnott, Rotman Research Institute, Baycrest Centre, Toronto, ON, M6A 2E1 Canada (e-mail: sarnott@rotman-baycrest.on.ca).

\section{REFERENCES}

Anderson, J. R., \& Meno, P. (2003). Psychological influences on yawning in children. Current Psychology Letters. Retrieved December 12, 2008, from http://cpl.revues.org/document390.html.

Anderson, J. R., Myowa-Yamakoshi, M., \& Matsuzawa, T. (2004). Contagious yawning in chimpanzees. Proceedings of the Royal Society $B, 271,468-470$.

BAENNINGER, R. (1987). Some comparative aspects of yawning in Betta splendens, Homo sapiens, Panthera leo, and Papio sphinx. Journal of Comparative Psychology, 101, 349-354.

BAENNINGER, R., \& Greco, M. (1991). Some antecedents and consequences of yawning. Psychological Record, 41, 453-460.

Baron-Cohen, S., \& Wheelwright, S. (2004). The empathy quotient: An investigation of adults with Asperger syndrome or high functioning autism, and normal sex differences. Journal of Autism \& Developmental Disorders, 34, 163-175.

Beerda, B., Schilder, M. B. H., van Hooff, J. A. R. A. M., de Vries, H. W., \& Mol, J. A. (1998). Behavioural, saliva cortisol and heart rate responses to different types of stimuli in dogs. Applied Animal Behaviour Science, 58, 365-381.

BookHEIMER, S. (2002). Functional MRI of language: New approaches to understanding the cortical organization of semantic processing. Annual Review of Neuroscience, 25, 151-188.

Chartrand, T. L., \& Bargh, J. A. (1999). The chameleon effect: The perception-behavior link and social interaction. Journal of Personality \& Social Psychology, 76, 893-910.

Cox, R. W. (1996). AFNI: Software for analysis and visualization of functional magnetic resonance neuroimages. Computers \& Biomedical Research, 29, 162-173.

Daquin, G., Micallef, J., \& Blin, O. (2001). Yawning. Sleep Medicine Reviews, 5, 299-312.

Deputte, B. L. (1994). Ethological study of yawning in primates: I. Quantitative-analysis and study of causation in two species of Old World monkeys (Cercocebus albigena and Macaca fascicularis). Ethology, 98, 221-245.

di Pellegrino, G., Fadiga, L., Fogassi, L., Gallese, V., \& RizzoLATTI, G. (1992). Understanding motor events: A neurophysiological study. Experimental Brain Research, 91, 176-180.

Egerman, R. S., \& Emerson, D. S. (1996). Images in clinical medicine. A fetal yawn. New England Journal of Medicine, 335, 1497.

Fadiga, L., Fogassi, L., Pavesi, G., \& Rizzolatti, G. (1995). Motor facilitation during action observation: A magnetic stimulation study. Journal of Neurophysiology, 73, 2608-2611.

Falck-Ytter, T., Gredebäck, G., \& von Hofsten, C. (2006). Infants predict other people's action goals. Nature Neuroscience, $\mathbf{9}$, 878-879.

Galati, G., Committeri, G., Spitoni, G., Aprile, T., Di Russo, F., Pitzalis, S., \& Pizzamiglio, L. (2008). A selective representation of the meaning of actions in the auditory mirror system. NeuroImage, 40, 1274-1286.

Gallese, V., Fadiga, L., Fogassi, L., \& Rizzolatti, G. (1996). Action recognition in the premotor cortex. Brain, 119, 593-609.

Gallese, V., Keysers, C., \& Rizzolatti, G. (2004). A unifying view of the basis of social cognition. Trends in Cognitive Sciences, 8, 396-403.

GAlluP, A. C., \& GALlup, G. G., JR. (2007). Yawning as a brain cooling mechanism: Nasal breathing and forehead cooling diminish the incidence of contagious yawning. Evolutionary Psychology, 5, 92-101.

Gazzola, V., Aziz-Zadeh, L., \& Keysers, C. (2006). Empathy and the somatotopic auditory mirror system in humans. Current Biology, 16, 1824-1829.

Gernsbacher, M. A., \& KaschaK, M. P. (2003). Neuroimaging studies of language production and comprehension. Annual Review of Psychology, 54, 91-114.

IACовоNI, M. (2005). Neural mechanisms of imitation. Current Opinion in Neurobiology, 15, 632-637.

JEANNEROD, M. (1994). The representing brain. Neural correlates of motor intention and imagery. Behavioral \& Brain Sciences, 17, 187-245.

Joly-Mascheroni, R. M., Senju, A., \& Shepherd, A. J. (2008). Dogs catch human yawns. Biology Letters, 4, 446-448.

JUNG-BEEMAN, M. (2005). Bilateral brain processes for comprehending natural language. Trends in Cognitive Sciences, 9, 512-518.

KAPLAN, J. T., \& IaCoboni, M. (2006). Getting a grip on other minds: Mirror neurons, intention understanding, and cognitive empathy. Social Neuroscience, 1, 175-183.

Keysers, C., \& Gazzola, V. (2006). Towards a unifying neural theory of social cognition. Progress in Brain Research, 156, 379-401.

Keysers, C., Kohler, E., Umiltà, M. A., Nanetti, L., Fogassi, L., \& Gallese, V. (2003). Audiovisual mirror neurons and action recognition. Experimental Brain Research, 153, 628-636.

Kohler, E., Keysers, C., Umiltà, M. A., Fogassi, L., Gallese, V., \& Rizzolatti, G. (2002). Hearing sounds, understanding actions: Action representation in mirror neurons. Science, 297, 846-848.

Laurent-Vannier, A., Fadda, G., Laigle, P., Dusser, A., \& LeroyMalherbe, V. (1999). Syndrome de Foix-Chavany-Marie d'origine traumatique chez l'enfant [Foix-Chavany-Marie syndrome in a child caused by head trauma]. Revue Neurologique, 155, 387-390.

Lee, T.-W., Josephs, O., Dolan, R. J., \& Critchley, H. D. (2006). Imitating expressions: Emotion-specific neural substrates in facial mimicry. Social Cognitive \& Affective Neuroscience, 1, 122-135.

Lehmann, H. E. (1979). Yawning: A homeostatic reflex and its psychological significance. Bulletin of the Menninger Clinic, 43, 123-136.

MaKuUCHI, M. (2005). Is Broca's area crucial for imitation? Cerebral Cortex, 15, 563-570.

Meyer, M., Baumann, S., Wildgruber, D., \& Alter, K. (2007). How the brain laughs: Comparative evidence from behavioural, electrophysiological and neuroimaging studies in human and monkey. $B e-$ havioural Brain Research, 182, 245-260.

MeYer, M., \& JÄNCKE, L. (2006). Involvement of the left and right frontal operculum in speech and nonspeech perception and production. 
In Y. Grodzinsky \& K. Amunts (Eds.), Broca's region (pp. 218-241). New York: Oxford University Press.

Moore, J. E. (1942). Some psychological aspects of yawning. Journal of General Psychology, 27, 289-294.

Oberman, L. M., \& Ramachandran, V. S. (2007). The simulating social mind: The role of the mirror neuron system and simulation in the social and communicative deficits of autism spectrum disorders. Psychological Bulletin, 133, 310-327.

Paukner, A., \& Anderson, J. R. (2006). Video-induced yawning in stumptail macaques (Macaca arctoides). Biology Letters, 2, 36-38.

Pazzaglia, M., Pizzamiglio, L., Pes, E., \& Aglioti, S. M. (2008). The sound of actions in apraxia. Current Biology, 18, 1766-1772.

Pfeifer, J. H., Iacoboni, M., Mazziotta, J. C., \& Dapretto, M. (2008). Mirroring others' emotions relates to empathy and interpersonal competence in children. NeuroImage, 39, 2076-2085.

Piaget, J. (1951). Play, dreams and imitation in childhood. New York: Norton.

Platek, S. M., Critton, S. R., Myers, T. E., \& Gallup, G. G., Jr. (2003). Contagious yawning: The role of self-awareness and mental state attribution. Cognitive Brain Research, 17, 223-227.

PlateK, S. M., Mohamed, F. B., \& Gallup, G. G., JR. (2005). Contagious yawning and the brain. Cognitive Brain Research, 23, 448-452.

Provine, R. R. (1986). Yawning as a stereotyped action pattern and releasing stimulus. Ethology, 72, 109-122.

Provine, R. R. (2005). Yawning. American Scientist, 93, 532-539.

Provine, R. R., \& Hamernik, H. B. (1986). Yawning: Effects of stimulus interest. Bulletin of the Psychonomic Society, 24, 437-438.

REDICAN, W. K. (1975). Facial expressions in nonhuman primates. In L. A. Roseblum (Ed.), Primate behavior: Developments in field and laboratory research (Vol. 4, pp. 103-194). New York: Academic Press.

Rizzolatti, G., \& Craighero, L. (2004). The mirror-neuron system. Annual Review of Neuroscience, 27, 169-192.

Rizzolatti, G., Fadiga, L., Gallese, V., \& Fogassi, L. (1996). Premotor cortex and the recognition of motor actions. Cognitive Brain Research, 3, 131-141.

Rogers, S. J., Hepburn, S. L., Stackhouse, T., \& Wehner, E. (2003). Imitation performance in toddlers with autism and those with other developmental disorders. Journal of Child Psychology \& Psychiatry, 44, 763-781.

Schürmann, M., Hesse, M. D., Stephan, K. E., Saarela, M., ZiLles, K., HARI, R., \& FUNK, G. R. (2005). Yearning to yawn: The neural basis of contagious yawning. NeuroImage, 24, 1260-1264.

Senju, A., Maeda, M., Kikuchi, Y., Hasegawa, T., Tojo, Y., \& Osa-
NAI, H. (2007). Absence of contagious yawning in children with autism spectrum disorder. Biology Letters, 3, 706-708.

Sepulveda, W., \& Mangiamarchi, M. (1995). Fetal yawning. Ultrasound in Obstetrics \& Gynecology, 5, 57-59.

Szameitat, A. J., Shen, S., \& Sterr, A. (2007). Motor imagery of complex everyday movements. An fMRI study. NeuroImage, 34, $702-713$.

TAlairach, J., \& Tournoux, P. (1988). Co-planar stereotaxic atlas of the human brain. New York: Thieme.

van der Gaag, C., Minderaa, R. B., \& Keysers, C. (2007). Facial expressions: What the mirror neuron system can and cannot tell us. Social Neuroscience, 2, 179-222.

Villarreal, M., Fridman, E. A., Amengual, A., Falasco, G., GersCOVICH, E. R., UlloA, E. R., \& Leiguarda, R. C. (2008). The neural substrate of gesture recognition. Neuropsychologia, 46, 2371-2382.

WALUSINSKI, O. (2006). Yawning: Unsuspected avenue for a better understanding of arousal and interoception. Medical Hypotheses, 67, 6-14.

Warren, J. E., Sauter, D. A., Eisner, F., Wiland, J., Dresner, M. A., Wise, R. J. S., ET AL. (2006). Positive emotions preferentially engage an auditory-motor "mirror" system. Journal of Neuroscience, 26, 13067-13075.

Wicker, B., Keysers, C., Plailly, J., Royet, J. P., Gallese, V., \& RizZolatti, G. (2003). Both of us disgusted in My insula: The common neural basis of seeing and feeling disgust. Neuron, 40, 655-664.

\section{NOTE}

1. A recent intriguing report of dogs yawning after observing human (strangers) yawn (Joly-Mascheroni, Senju, \& Shepherd, 2008) requires further investigation, since the yawning could have reflected heightened anxiety (Beerda, Schilder, van Hooff, de Vries, \& Mol, 1998; Deputte, 1994) either to the auditory stimulation (absent in the control condition) and/or the amount of teeth baring that was present in the experimental condition.

\section{SUPPLEMENTAL MATERIALS}

A supplemental figure depicting results from right posterior IFG may be downloaded from http://cabn.psychonomic-journals.org/content/ supplemental.

(Manuscript received December 31, 2008; revision accepted for publication March 15, 2009.) 